\title{
Article \\ Selective Oxidation of Transient Organic Radicals in the Presence of Gold Nanoparticles
}

\author{
Viacheslav Shcherbakov (D), Sergey A. Denisov * (1) and Mehran Mostafavi * \\ Institute de Chimie Physique (ICP), CNRS/Université Paris-Saclay, 91405 Orsay, France; \\ viacheslav.shcherbakov@universite-paris-saclay.fr \\ * Correspondence: sergey.denisov@universite-paris-saclay.fr (S.A.D.); \\ mehran.mostafavi@universite-paris-saclay.fr (M.M.)
}

check for updates

Citation: Shcherbakov, V.; Denisov,

S.A.; Mostafavi, M. Selective

Oxidation of Transient Organic Radicals in the Presence of Gold Nanoparticles. Nanomaterials 2021, 11, 727. https://doi.org/10.3390/ nano11030727

Academic Editor: Sónia Carabineiro

Received: 25 February 2021

Accepted: 12 March 2021

Published: 14 March 2021

Publisher's Note: MDPI stays neutral with regard to jurisdictional claims in published maps and institutional affiliations.

Copyright: (c) 2021 by the authors. Licensee MDPI, Basel, Switzerland. This article is an open access article distributed under the terms and conditions of the Creative Commons Attribution (CC BY) license (https:/ / creativecommons.org/licenses/by/ $4.0 /)$.
Abstract: The ability of gold nanoparticles (AuNPs) to catalyze reactions involving radicals is poorly studied. However, AuNPs are used in applications where chemical reactions involving transient radicals occur. Herein, we investigate AuNPs' catalytic effect on 2-propanol oxidation and acetanilide hydroxylation in aqueous solutions under ionizing radiation at room temperature. In both cases, the presence of AuNPs led to selective oxidation of organic radicals, significantly changing the products' composition and ratio. Based on these observations, we stress how AuNPs' catalytic activity can affect the correctness of reactive oxygen species concentration determination utilizing organic dyes. We also provide a discussion on the role of AuNPs' catalytic activity in the radiosensitization effect actively studied for radiotherapy.

Keywords: gold nanoparticle; radical; ROS; catalysis; oxidation; radiolysis; radiosensitization

\section{Introduction}

For a long time, gold was not considered a promising catalyzer. In early studies, gold demonstrated less catalytic activity for hydrogenation and dehydrogenation than $\mathrm{Pt}$ and $\mathrm{Pd}[1,2]$. However, 15 years later, it was found that small gold particles on $\alpha-\mathrm{Fe}_{2} \mathrm{O}_{3}$, $\mathrm{Co}_{3} \mathrm{O}_{4}$, or $\mathrm{NiO}$ supports efficiently catalyze $\mathrm{CO}$ oxidation at low temperatures [3]. This finding provoked great interest in studying the catalytic properties of gold nanoparticles (AuNPs) [4]. The industrial search for promising catalyzers led to a bias in research towards supported AuNPs compared to gold colloids [5].

For the first time, the catalytic activity of AuNPs under normal conditions was demonstrated by radiation chemistry and electrochemistry communities in the 1980s [6,7]. In electrochemistry, gold and other conductive nanoparticles, e.g., silver, have been studied to catalyze redox reactions $[8,9]$, while in radiation chemistry, such properties were used mainly to increase hydrogen production in aqueous solutions of alcohols under radiation [10-12]. Nonetheless, these works went unnoticed. Even in radiation chemistry, there are only a few examples studying the interaction of AuNPs with transient organic radicals not devoted to $\mathrm{H}_{2}$ production [13-15]. For example, nitroxyl-free radicals' interaction with AuNPs was studied by electron paramagnetic resonance spectroscopy, which confirmed the interaction of unpaired electrons with the AuNP's surface [16]. Lien et al. [17], using a 5-tert-butoxycarbonyl-5-methyl-1-pyrroline $\mathrm{N}$-oxide (BMPO) spin trap for ${ }^{\bullet} \mathrm{OH}$ radicals, showed that AuNPs catalyze the conversion of ${ }^{\bullet} \mathrm{BMPO}-\mathrm{OH}$ radical to ${ }^{\bullet} \mathrm{BMPO}-\mathrm{H}$ radical.

Understanding AuNPs' catalytic effect is essential for biomedical applications [18-20], where these particles are still often considered an inert material, such as bulk gold [21]. Considering the findings on catalytic properties, one can assume that AuNPs could alter cell metabolism by oxidizing organic radicals naturally produced in the cell due to the presence of reactive oxygen species (ROS) such as hydroxyl radical $\left({ }^{\bullet} \mathrm{OH}\right)$, superoxide radical $\left(\mathrm{O}_{2}{ }^{\bullet-}\right)$, and hydrogen peroxide $\left(\mathrm{H}_{2} \mathrm{O}_{2}\right)$. 
Despite the pioneering works utilizing AuNPs as catalysts in radiation chemistry, their catalytic activity is neglected in radiotherapy research, where they represent an essential class of radiosensitizing agents-materials that increase radiation damage [22]. The radiosensitizing effect was initially explained by a physical dose enhancement due to the higher mass energy-absorption coefficient of gold than water/soft tissues [23,24]. Nowadays, it is clear that the effect is much more complex and involves different physical, chemical, and biological processes [24-28]. The catalytic activity of AuNPs in radiosensitization studies is mainly mentioned in the context of ROS production, which is claimed as one of the mechanisms of AuNPs' radiosensitizing effect [25,27]. However, in recent work, we showed that at a therapeutically relevant gold concentration $(<3 \mathrm{mM}$ atomic gold, $<600 \mu \mathrm{g} \mathrm{cm}^{-3}$ ), the presence of gold nanoparticles does not induce higher primary radicals formation [29].

It is important to note that ROS are generally measured by an indirect method using fluorescence spectroscopy with organic dyes [27]. This method is based on converting a nonfluorescence molecule into a fluorescent one in reaction with ROS [30,31]. The amount of formed fluorescence product is claimed to be proportional to ROS concentration. However, the mechanism of such oxidation is complex. The oxidation always occurs through the formation of transient radicals. Therefore, not considering the catalytic activity of AuNPs towards transient organic radicals can lead to incorrect determination of ROS concentration.

In this work, we focus on the oxidation of transient organic radicals in the presence of AuNPs. We have studied two types of organic radicals produced by ${ }^{\bullet} \mathrm{OH}$ radical attack: $\mathrm{H}$ atom abstraction from 2-propanol and ${ }^{\bullet} \mathrm{OH}$ attachment to a benzene ring of acetanilide. In both cases, the presence of AuNPs led to selective oxidation of organic radicals. By extrapolating our results, we discuss AuNPs' catalytic activity's effect on ROS detection by fluorescent dyes, its potential role in explaining the radiosensitizing effect of AuNPs reported in the literature, and general precautions of utilizing AuNPs in biomedical applications.

\section{Materials and Methods}

\subsection{Chemicals}

Gold nanoparticle synthesis: potassium gold (III) chloride (98\%), sodium borohydride (98\%), and sodium citrate (99\%) were purchased from Sigma Aldrich (St. Quentin Fallavier, France). Sodium chloride (99.9\%) was purchased from VWR chemicals (VWR International Inc., Fontenay-sous-Bois, France), and 2-propanol (99.5\%, Sigma Aldrich, St. Quentin Fallavier, France) was used as a hydroxyl radical scavenger. Acetone (99.8\%, Sigma Aldrich, St. Quentin Fallavier, France) and $\mathrm{N}_{2} \mathrm{O}$ (Alpha Gaz, Air Liquide, Paris, France) were used as hydrated electron scavengers. Ar (Alpha Gaz, Air Liquide, Paris, France) was used for deoxygenation. Acetanilide ( $\leq 100 \%$, Jeulin, Évreux, France) was used as a model for hydroxylation reaction. Furthermore, 2-Hydroxyacetanilide $(97 \%)$ and 3-Hydroxyacetanilide (99+\%) purchased from Acros Organics (Fisher Scientific, Illkirch, France) and 4-Hydroxyacetanilide (>99\%) purchased from Sigma-Aldrich (St. Quentin Fallavier, France) were used as standards for HPLC. All chemicals were used without additional purification. Water (Milli-Q, Merck KGaA, Darmstadt, Germany) with a resistivity of $18 \mathrm{M} \Omega \mathrm{cm}$ was used in all experiments.

\subsection{Synthesis of AuNPs}

AuNPs were prepared by reduction with sodium borohydride: $3 \mathrm{~mL}$ of $100 \mathrm{mM}$ stock solution of gold salt was mixed with $87.7 \mathrm{~mL}$ of deionized water, and $9.3 \mathrm{~mL}$ of $100 \mathrm{mM}$ $\mathrm{NaBH}_{4}$ was added to the solution while stirring for $15 \mathrm{~min}$. The solution changed color from yellow to dark red on the reduction of gold ions. The final concentration of gold salt was $3 \mathrm{mM}$. The particles were stable for weeks. Their zeta potential was $-20 \mathrm{mV}$ (Zetasizer Nano ZS, Malvern, Palaiseau, France). The maximum wavelength of the plasmon band was $520 \mathrm{~nm}$. 
The diameters of nanoparticles were determined from the maximum wavelength of the AuNPs' plasmon band (520 nm) [32] and theirs size (20 nm) was confirmed by transmission electron microscopy (STEM 1400, JEOL Ltd., Tokio, Japan). The pH of the solutions was $\sim 7$. All experiments were conducted at $22.5^{\circ} \mathrm{C}$.

The concentration of particles was calculated as follows:

$$
C_{\mathrm{AuNP}}=\frac{6 M_{w} C}{\pi \rho d^{3} \mathrm{~N}_{A}}
$$

where $M_{w}$ : gold molecular weight $(197 \mathrm{~g} / \mathrm{mol}) ; C$ : molar atomic gold concentration; $\rho$ : density of bulk gold (19.32 $\left.\mathrm{g} \mathrm{cm}^{-3}\right) ; \mathrm{N}_{A}$ : Avogadro number; and $d$ : diameter of particles.

\subsection{Gamma Radiolysis}

A ${ }^{60} \mathrm{Co} \gamma$ source was used for steady-state radiolysis experiments. The dose rate was verified by Frick dosimetry. No dose rate dependence was observed in the used dose rate ranges in both experiments. Samples were irradiated in glass bottles. AuNPs were precipitated by the addition of $\mathrm{NaCl}$ up to $0.5 \mathrm{wt}$ \% and centrifugation utilizing an Eppendorf MiniSpin centrifuge (Eppendorf Inc., Montesson, France) with F-45-12-11 rotor at a speed of 13,400 rpm for $30 \mathrm{~min}$. The samples were placed in 2-mL Eppendorf microtubes.

\subsection{2-Propanol Oxidation}

Briefly, $4 \mathrm{~mL}$ of an aqueous solution containing $100 \mathrm{mM}$ of 2-propanol and $20 \mathrm{mM}$ of acetone and AuNP suspension (12 nM particle concentration) with the same amount of 2-propanol and acetone were irradiated at various doses. The dose rate was in the range between 0.2 and $4 \mathrm{kGy} \mathrm{h}^{-1}$. All samples $(4 \mathrm{~mL})$ were deoxygenated by bubbling with $\mathrm{Ar}$ for $10 \mathrm{~min}$. The acetone concentration formed during irradiation was determined by the acetone absorbance band at $265 \mathrm{~nm}$ using UV-Vis absorption spectrophotometry (Hewlett Packard 8453 spectrophotometer, Hewlett Packard Inc., Puteaux, France). The extinction coefficient of $15.4 \mathrm{M}^{-1} \mathrm{~cm}^{-1}$ determined in the laboratory is within the literature data [33].

\subsection{Acetanilide Hydroxylation}

Briefly, $2 \mathrm{~mL}$ of $0.5 \mathrm{mM}$ acetanilide aqueous solution in the absence and presence

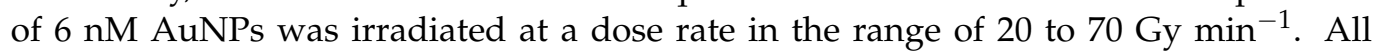
samples $\left(2 \mathrm{ml}\right.$ ) were saturated with $\mathrm{N}_{2} \mathrm{O}$ by bubbling for $10 \mathrm{~min}$. Irradiated samples were analyzed by high-performance liquid chromatography (Agilent Technologies 1260 infinity, Agilent Technologies, Les Ulis, France). A diode-array detector was used to record the light intensity in the range from 200 to $500 \mathrm{~nm}$. The HPLC column was EC 50/4.6 Nucleoshell RP 18plus, $2.7 \mu \mathrm{m}$. A mixture of $97 \%$ water and $3 \%$ acetonitrile was used for isocratic elution at a rate of $1.5 \mathrm{~mL} \mathrm{~min}{ }^{-1}$. The products of acetanilide hydroxylation were determined by comparing their spectra and retention time with commercial standards.

\section{Results}

The ${ }^{\bullet} \mathrm{OH}$ radicals were produced by water radiolysis under gamma radiation $\left({ }^{60} \mathrm{Co}\right)$. The radiolytic yields $\left(\mathrm{G}, \mathrm{mol} \mathrm{J}^{-1}\right)$ of primary water radicals and molecules are well established and represent the number of molecules produced per joule of energy. We have used standard values for the homogenous step of water radiolysis (1); G values $\left(\times 10^{-7} \mathrm{~mol} \mathrm{~J}-1\right)$ are given in brackets [34].

$$
\mathrm{H}_{2} \mathrm{O} \stackrel{\gamma}{\rightarrow} \mathrm{e}_{\mathrm{aq}}^{-}(2.8), \mathrm{H}_{3} \mathrm{O}^{+},{ }^{\bullet} \mathrm{H}(0.6), \bullet \cdot \mathrm{OH}(2.8), \mathrm{H}_{2} \mathrm{O}_{2}(0.7)
$$

All experiments were carried out with AuNPs of $20 \mathrm{~nm}$ in diameter, synthesized using sodium borohydride as a reduction agent (see Section 2 and Figure S1). The suspensions with a concentration of gold atoms of 3 and $1.5 \mathrm{mM}$ correspond to 12 and $6 \mathrm{nM}$ of $20-\mathrm{nm}$ particles, respectively. Pure water was used as a reference. A series of experiments were 
conducted to prove that water and supernatant show similar results (Figure S2), which proved that water could be considered an appropriate reference.

\subsection{Oxidation of Organic Radical Produced by $\bullet H$ Atom Abstraction}

As mentioned in the Introduction, metal nanoparticles have been shown to increase hydrogen production in irradiated aqueous solutions of aliphatic alcohols [10-12]. This phenomenon was explained by the catalytic reduction in water on the metal surface. However, another side of the process, namely the oxidation of organic radicals which work as electron donors, has never been studied.

Therefore, we first investigated the AuNPs' effect on 2-propanol oxidation following acetone formation in an irradiated aqueous solution containing $100 \mathrm{mM}$ of 2-propanol and $20 \mathrm{mM}$ of acetone saturated with Ar.

The acetone concentration was determined by optical absorption measurements at $265 \mathrm{~nm}$ using an extinction coefficient of $15.4 \mathrm{M}^{-1} \mathrm{~cm}^{-1}$ (Figure S3) in the supernatants of AuNP suspensions (see Section 2 for details). The acetone's radiolytic formation yield was determined from acetone concentration dependence versus the applied dose (Figure 1). In this experiment, the applied dose was relatively high (up to $220 \mathrm{kGy}$ ) to accumulate a measurable quantity of acetone.

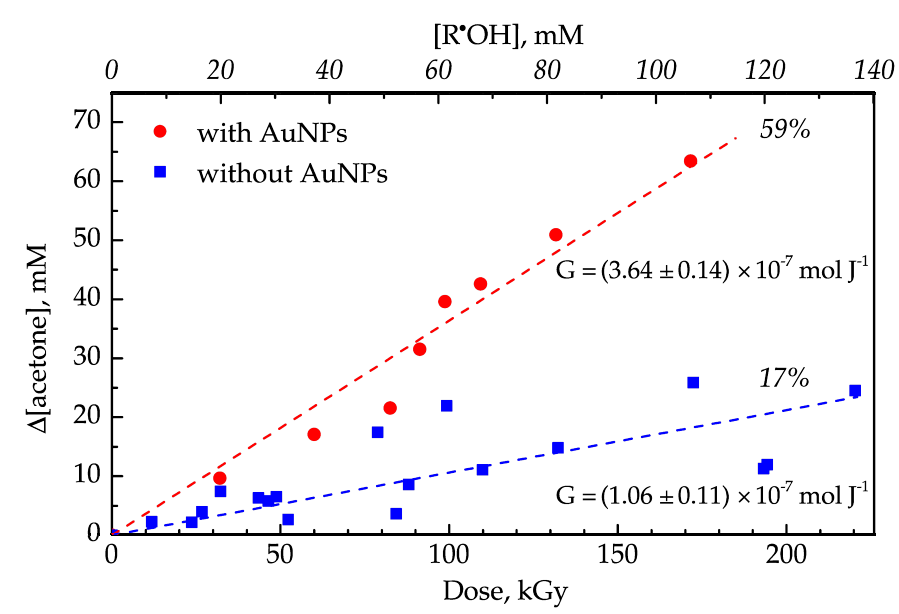

Figure 1. Acetone formation in the aqueous solution containing $100 \mathrm{mM}$ 2-propanol and ca. $20 \mathrm{mM}$ of acetone (blue squares) and in the gold nanoparticle (AuNP) suspension (12 nM particle concentration) containing the same amount of 2-propanol and acetone (red dots) irradiated by gamma rays at various doses. All samples were deoxygenated by bubbling with Ar. Radiolytic yield (G) of acetone is determined from a linear slope. Reaction yield is calculated as a percentage of $\mathrm{R}^{\bullet} \mathrm{OH}$ oxidation to acetone.

The first step of 2-propanol ( $\mathrm{ROH})$ oxidation in irradiated aqueous solution is a hydrogen atom abstraction, mainly from the alpha carbon, by ${ }^{\bullet} \mathrm{OH}$ and ${ }^{\bullet} \mathrm{H}$ radicals, forming $\alpha$-hydroxyisopropyl radical $\left(\mathrm{R}^{\bullet} \mathrm{OH}\right)$ (Scheme 1 reactions 1-2) [35]. In the presence of acetone $(20 \mathrm{mM})$, hydrated electrons $\left(\mathrm{e}^{-}\right.$aq $)$are entirely scavenged by acetone, forming the same $\mathrm{R}^{\bullet} \mathrm{OH}$ radical (Scheme 1 reaction 3). 


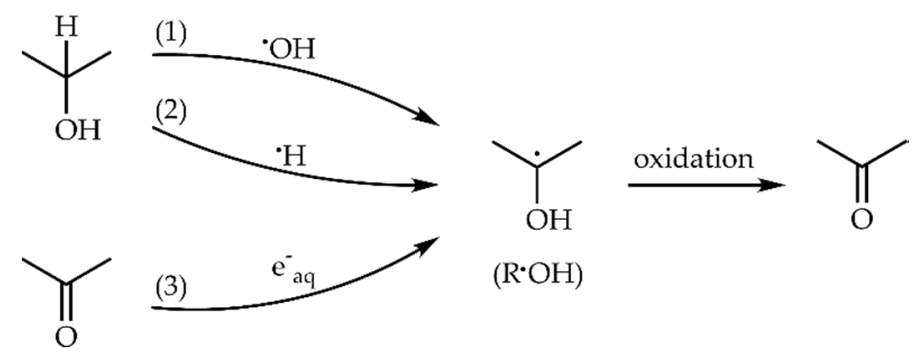

Scheme 1. Acetone formation through the oxidation of $\alpha$-hydroxyisopropyl radical formed in the irradiated aqueous solution of 2-propanol and acetone.

Based on these reactions (Scheme 1), the maximum radiolytic yield of $\mathrm{R}^{\bullet} \mathrm{OH}$ can be calculated according to the equation: $\mathrm{G}\left(\mathrm{R}^{\bullet} \mathrm{OH}\right)=\mathrm{G}\left(\mathrm{e}_{\mathrm{aq}}^{-}\right)+\mathrm{G}\left(\bullet^{\bullet} \mathrm{OH}\right)+\mathrm{G}\left(\mathrm{H}^{\bullet}\right)=$ $6.2 \times 10^{-7} \mathrm{~mol} \mathrm{~J}^{-1}$. The $\mathrm{R}^{\bullet} \mathrm{OH}$ concentration can be calculated by multiplication of the radiolytic yield by dose (Figure 1, top axis).

The oxidation of the $\mathrm{R}^{\bullet} \mathrm{OH}$ radical leads to acetone formation. We found that in the presence of AuNPs (12 $\mathrm{nM}$ of $20 \mathrm{~nm}$ ), acetone formation is 3.5 times higher than in water (Figure 1), which corresponds to $59 \%$ and $17 \%$ of the maximum yield, respectively.

This difference can be explained by direct oxidation of the $\mathrm{R}^{\bullet} \mathrm{OH}$ radical in the presence of AuNPs, instead of a well-known disproportionation reaction occurring between two $\mathrm{R}^{\bullet} \mathrm{OH}$ radicals, leading to acetone formation.

The $\mathrm{R}^{\bullet} \mathrm{OH}$ oxidation in the presence of AuNPs suggests an electron transfer from the radical to the particle, as reported previously $[8,36]$. Conducting nanoparticles can accumulate a negative charge by uptaking unpaired electrons from the $\alpha$-hydroxyisopropyl radical [36], which is supported by the concept of "floating electrocatalysis" [8]. The excess charge on the particle can be taken by electron acceptors, such as $\mathrm{H}^{+}$or $\mathrm{H}_{2} \mathrm{O}$ in deaerated solutions, to fulfill the requirement of electroneutrality. AuNPs work as an electron relay conducting electron from a donor to an acceptor [37].

\subsection{Oxidation of Organic Radicals Produced by $\bullet \mathrm{OH}^{-1 t a c h m e n t}$}

The ${ }^{\bullet} \mathrm{OH}$ radical can not only cause $\mathrm{H}$-abstraction, but it also could form an ${ }^{\bullet} \mathrm{OH}$ adduct. Therefore, to study the catalytic effect of AuNPs on such a type of reaction, we chose acetanilide hydroxylation by ${ }^{\bullet} \mathrm{OH}$, which is similar to other aromatic systems. It includes the following steps: attachment of ${ }^{\bullet} \mathrm{OH}$ to a benzene ring forming an adduct and the loss of an electron, followed by the loss of $\mathrm{H}^{+}$, forming a stable hydroxylated molecule (Scheme 2) [38,39]. In this reaction, numerous products are formed. Herein, we focused on three main products: hydroxyacetanilide with a hydroxyl group in ortho, meta, para positions, and acetanilide consumption (Figure 2).

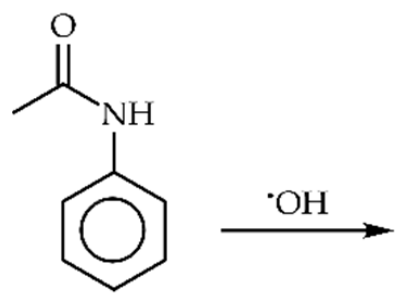

acetanilide<smiles>CC(=O)NC1=CC=CCC1(C)O</smiles>

adduct

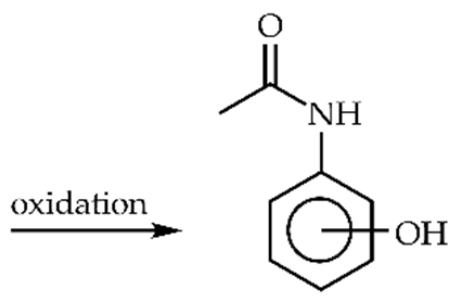

hydroxyacetanilide

Scheme 2. Acetanilide hydroxylation by ${ }^{\bullet} \mathrm{OH}$ radical. 


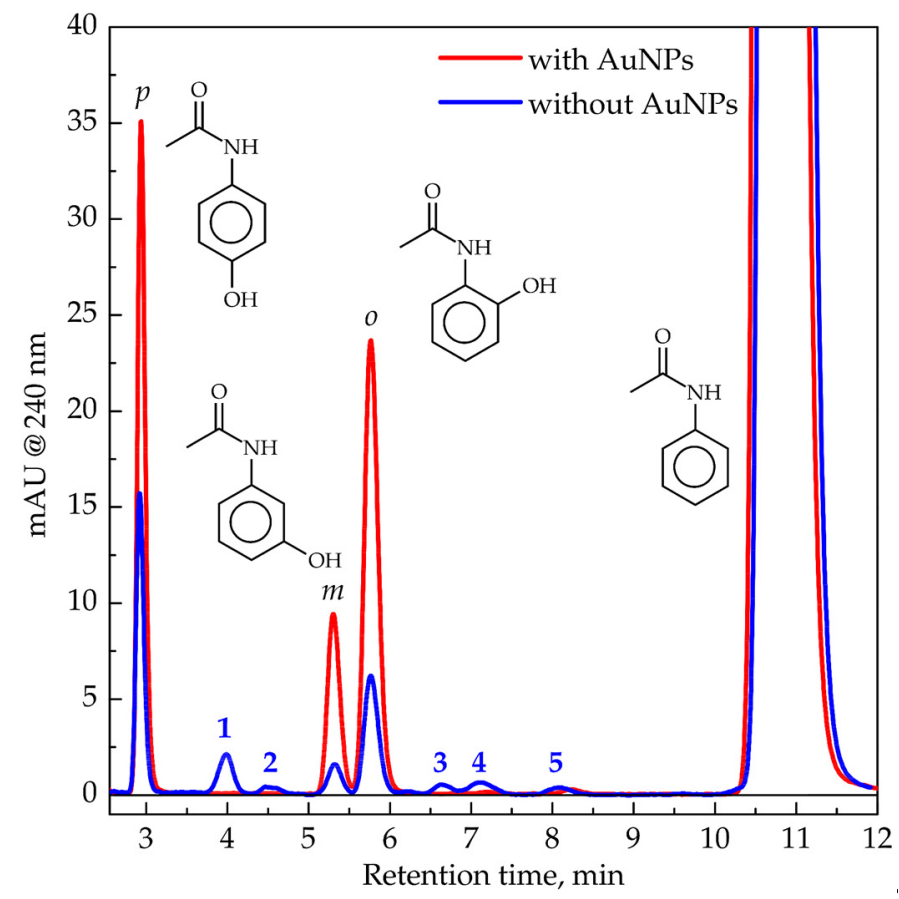

Figure 2. Chromatograms of $0.5 \mathrm{mM}$ acetanilide aqueous solution (blue) and $0.5 \mathrm{mM}$ of acetanilide in AuNP suspension with $6 \mathrm{nM}$ particle concentration (red) after 90-Gy dose deposition by gamma rays. Samples were deoxygenated and saturated with $\mathrm{N}_{2} \mathrm{O}$. Molecules from left to right: parahydroxyacetanilide, meta-hydroxyacetanilide, ortho-hydroxyacetanilide, and acetanilide.

Aqueous solutions of $0.5 \mathrm{mM}$ acetanilide with and without $6 \mathrm{nM}$ of AuNPs were irradiated $\left({ }^{60} \mathrm{Co}\right)$ under a $\mathrm{N}_{2} \mathrm{O}$ atmosphere to convert all hydrated electrons to ${ }^{\bullet} \mathrm{OH}$ radicals (reaction S1 in Supplementary Materials).

The first observation consists of a drastic decrease in the number of products in the presence of AuNPs. Products numbered from 1 to 5 in Figure 2 are not detected in the presence of AuNPs. Secondly, acetanilide consumption is only slightly different for samples with and without AuNPs (Figure 3a). In the absence of AuNPs, the yield of acetanilide disappearance $\left(5.0 \times 10^{-7} \mathrm{~mol} \mathrm{~J}^{-1}\right)$ is lower than the yield of $\bullet \mathrm{OH}$ radicals $\left(5.6 \times 10^{-7} \mathrm{~mol} \mathrm{~J}^{-1}\right.$, Equation (S1)). The reason for that is likely the disproportionation reaction between two adducts that re-form acetanilide. In the presence of AuNPs, the absolute value of acetanilide disappearance is equal to the yield of ${ }^{\bullet} \mathrm{OH}$ radicals. It means that direct oxidation of acetanilide adducts by AuNPs dominates over the disproportionation reaction. Moreover, this result indicates that AuNPs do not induce higher ${ }^{\bullet} \mathrm{OH}$ radical production in contrast to the previously reported statement [27].

The total hydroxylation yield was increased four times from $20 \%$ to $79 \%$ (Table 1) in the presence of AuNPs (Figure 3b). Similar behavior was observed for phenylalanine oxidation under ionizing radiation in the presence of $\mathrm{Fe}(\mathrm{CN})_{6}{ }^{-3}$, leading to an increase in the formation yield of ortho-, meta-, and para-Tyrosine to $80 \%$ [39]. The remaining $20 \%$ was assumed to ${ }^{\bullet} \mathrm{OH}$ radical attachment to ipso position and ${ }^{\bullet} \mathrm{H}$ atom abstraction from the benzyl position, which do not lead to tyrosine formation. 


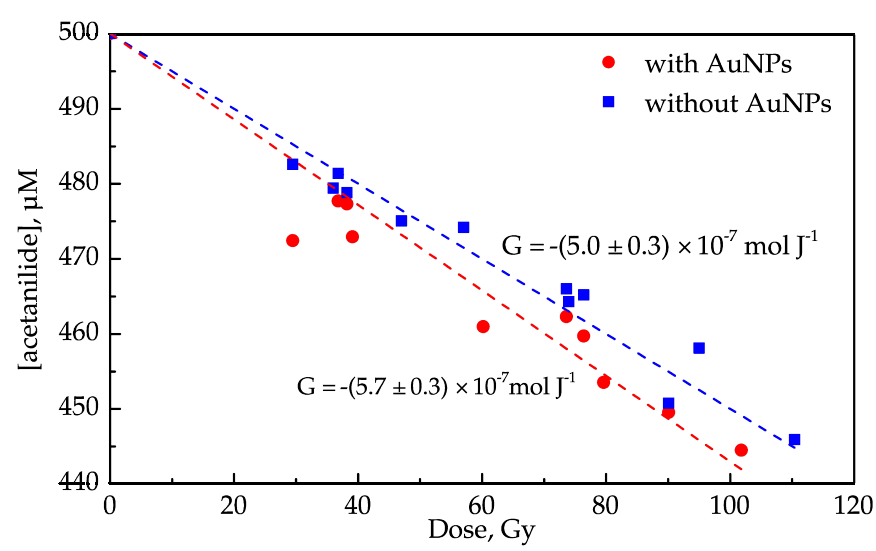

(a)

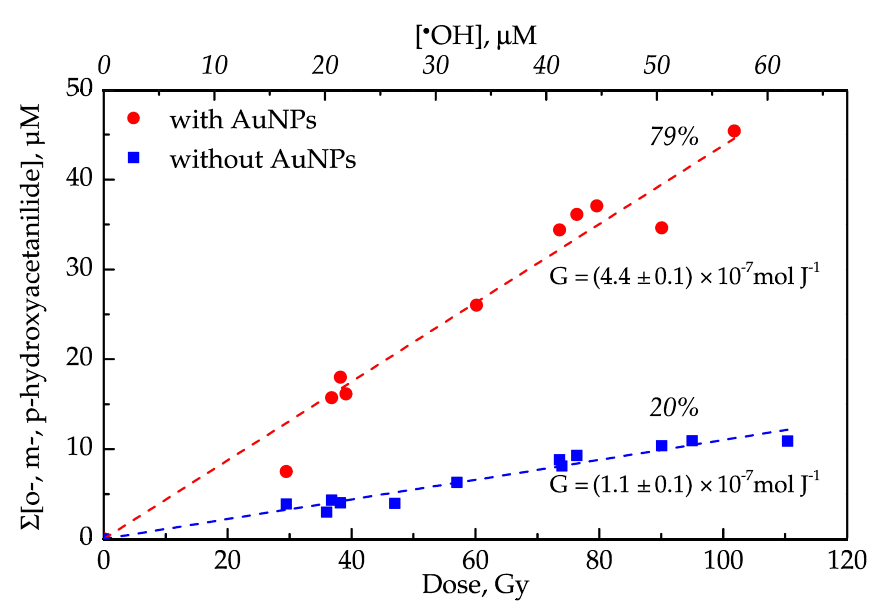

(b)

Figure 3. Analysis of $0.5 \mathrm{mM}$ acetanilide aqueous solution (blue squares) and $0.5 \mathrm{mM}$ of acetanilide in AuNPs' suspension with $6 \mathrm{nM}$ particle concentration (red dots) irradiated at various doses by gamma rays. (a) The disappearance of acetanilide; (b) the formation of ortho, meta, para-hydroxyacetanilide. All samples were saturated with $\mathrm{N}_{2} \mathrm{O}$ by bubbling. Radiolytic yields $(\mathrm{G})$ are determined from linear slopes. Reaction yields are calculated as a percentage of $\bullet \mathrm{OH}$ concentration.

Table 1. Acetanilide hydroxylation.

\begin{tabular}{cccc}
\hline & \multicolumn{2}{c}{ Reaction Yield } \\
\hline & With AuNPs & Without AuNPs & Ration \\
\hline p-hydroxyacetanilide & $22.5 \%$ & $7 \%$ & 3.2 \\
m-hydroxyacetanilide & $8.9 \%$ & $1.3 \%$ & 6.9 \\
o-hydroxyacetanilide & $46.6 \%$ & $11.6 \%$ & 4 \\
Total & $78.6 \%$ & $19.6 \%$ & 4 \\
\hline
\end{tabular}

${ }^{1}$ Reaction yield was calculated based on the concentration of ${ }^{\bullet} \mathrm{OH}$ radicals produced during water radiolysis, $\mathrm{G}\left(\bullet^{\bullet} \mathrm{OH}\right)=5.6 \times 10^{-7} \mathrm{~mol} \mathrm{~J}^{-1}$.

As in the case of 2-propanol, the radicals of acetanilide were selectively oxidized to hydroxyacetanilide in the presence of AuNPs.

\section{Discussion}

The usage of AuNPs in biomedical applications includes delivery, visualization, and radiosensitization $[19,20,25]$. For a long time, AuNPs were considered not only inert material but also not toxic. However, works appeared in the literature showing that gold nanoparticles do show toxic effects on cells [21].

Whenever the subject of AuNPs' toxicity is raised, the explanation is higher ROS production in their presence with and without ionizing radiation, based on ROS measurement using the fluorescence spectroscopy method [40-43]. This method is based on the change in the fluorescence properties of dye when it reacts with ROS such as hydroxyl radical $\left({ }^{\bullet} \mathrm{OH}\right)$, superoxide radical $\left(\mathrm{O}_{2}{ }^{\bullet-}\right)$, and hydrogen peroxide $\left(\mathrm{H}_{2} \mathrm{O}_{2}\right)$ [31]. For example, the detection of ${ }^{\bullet} \mathrm{OH}$ radicals is often based on a non-fluorescent probe molecule's hydroxylation, forming a fluorescent one $[30,44]$. The reaction scheme is similar to the acetanilide hydroxylation described above: the formation of a transient radical (adduct) followed by its oxidation, forming a hydroxylated molecule. Thus, disregarding important AuNP catalytic properties may lead to interpretation of the increased formation of hydroxylation products as ${ }^{\bullet} \mathrm{OH}$ overproduction [45-47] since the product's concentration is assumed to be proportional to ${ }^{\bullet} \mathrm{OH}$ concentration. Thus, detection of probe molecule consumption is a more appropriate indicator for ${ }^{\bullet} \mathrm{OH}$ detection. As we show here, the presence of AuNPs does not cause $\bullet^{\bullet} \mathrm{OH}$ overproduction, in agreement with our previous work [29]. 
The extrapolation of our results towards fluorescent dyes used to detect ROS other than ${ }^{\bullet} \mathrm{OH}$ in the presence of metal nanoparticles is less obvious but still reasonable, since oxidation is a two-electron transfer process which occurs through the formation of transient organic radicals. Those radicals can be catalytically oxidized in the presence of nanoparticles, causing misdetermination of ROS production [27]. Thus, the validity of utilizing fluorescent probes without considering the catalytic effect of AuNPs in the presence of metal nanoparticles is under question.

Our results have significant consequences on the understanding of the mechanism of AuNPs as radiosensitization. Nowadays, it is considered to occur through AuNPs' effect on different physical, chemical, and biological processes [24-28]. The radiosensitization mechanism is often discussed in the context of ROS overproduction in the presence of AuNPs [25,27]. However, AuNPs' catalytic properties towards radicals were never discussed before.

It is essential to mention that different organic radicals are always present in cells due to their metabolism. Therefore, AuNPs can change the cell chemistry affecting radicals' processes, even before ionizing radiation is applied, which, in principle, could shatter the cell's resistivity towards ionization radiation.

\section{Conclusions}

We studied AuNPs' catalytic activity towards the oxidation of two types of transient organic radicals produced by ${ }^{\bullet} \mathrm{OH}$ radical, namely by ${ }^{\bullet} \mathrm{H}$ atom abstraction from alpha carbon of 2-propanol, forming $\alpha$-hydroxyisopropyl radical, and ${ }^{\bullet} \mathrm{OH}$ radical attachment to the benzene ring of acetanilide, forming different adducts. In both cases, AuNPs caused selective oxidation of transient organic radicals. Thus, AuNPs increased acetone formation by 3.5 times in an irradiated aqueous solution of 2-propanol/acetone. In the case of acetanilide hydroxylation, the number of products was decreased in the presence of AuNPs, and the total hydroxylation was increased by four times. At the same time, the consumption of acetanilide was equal to the concentration of ${ }^{\bullet} \mathrm{OH}$ produced during water radiolysis. This result contradicts those previously reported in the literature of $\bullet \mathrm{OH}$ overproduction in the presence of AuNPs.

We also discussed the implication of our results in the explanation of the radiosensitizing effect of AuNPs. We proposed that AuNPs can affect cell chemistry by catalytic oxidation of organic radicals, which can be produced naturally or by ionizing radiation.

Supplementary Materials: The following are available online at https:/ /www.mdpi.com/2079-499 1/11/3/727/s1, Figure S1: Characterization of AuNPs; Figure S2: Acetone formation in the aqueous solution of 2-propanol $(100 \mathrm{mM})$ and a supernatant of AuNP suspension containing $100 \mathrm{mM}$ of 2-propanol irradiated by gamma rays at various doses; Figure S3: Spectra of AuNP suspension (12 $\mathrm{nM}$ particle concentration) containing $100 \mathrm{mM}$ of 2-propanol and $18 \mathrm{mM}$ of acetone irradiated with gamma rays at various doses; Reaction S1: Conversion of the hydrated electron ( $\mathrm{e}^{-}$aq $)$to ${ }^{\bullet} \mathrm{OH}$ radical by $\mathrm{N}_{2} \mathrm{O}$; Equation (S1): Radiolytic yield of ${ }^{\bullet} \mathrm{OH}$ radical under $\mathrm{N}_{2} \mathrm{O}$ atmosphere.

Author Contributions: Conceptualization, V.S., S.A.D., and M.M.; methodology, V.S. and M.M.; validation, V.S., S.A.D., and M.M.; formal analysis, V.S., S.A.D., and M.M.; investigation, V.S.; data curation, V.S.; writing-original draft preparation, V.S. and S.A.D.; writing-review and editing, V.S., S.A.D., and M.M.; visualization, V.S. and S.A.D.; supervision, S.A.D. and M.M.; project administration, S.A.D. and M.M. All authors have read and agreed to the published version of the manuscript.

Funding: Viacheslav Shcherbakov PhD grant has been received from Doctoral school (Ecole Doctorale 2MIB) of Paris-Saclay University

Conflicts of Interest: The authors declare no conflict of interest.

\section{References}

1. Bond, G.C. The catalytic properties of gold. Gold Bull. 1972, 5, 11-13. [CrossRef]

2. Bond, G.C.; Sermon, P.A. Gold catalysts for olefin hydrogenation-Transmutation of catalytic properties. Gold Bull. 1973, 6, 102-105. [CrossRef] 
3. Haruta, M.; Kobayashi, T.; Sano, H.; Yamada, N. Novel Gold Catalysts for the Oxidation of Carbon Monoxide at a Temperature far Below $0{ }^{\circ} \mathrm{C}$. Chem. Lett. 1987, 16, 405-408. [CrossRef]

4. Corma, A.; Garcia, H. Supported gold nanoparticles as catalysts for organic reactions. Chem. Soc. Rev. 2008, 37, 2096-2126. [CrossRef] [PubMed]

5. Mikami, Y.; Dhakshinamoorthy, A.; Alvaro, M.; García, H. Catalytic activity of unsupported gold nanoparticles. Catal. Sci. Technol. 2013, 3, 58-69. [CrossRef]

6. Meisel, D.; Mulac, W.A.; Matheson, M.S. Catalysis of Methyl Viologen Radical Reactions by Polymer-Stabilized Gold Sols. J. Phys. Chem. 1981, 85, 179-187. [CrossRef]

7. Freund, P.L.; Spiro, M. Colloidal Catalysis: The Effect of Sol Size and Concentration. J. Phys. Chem. 1985, 89, 1074-1077. [CrossRef]

8. Peljo, P.; Scanlon, M.D.; Olaya, A.J.; Rivier, L.; Smirnov, E.; Girault, H.H. Redox Electrocatalysis of Floating Nanoparticles: Determining Electrocatalytic Properties without the Influence of Solid Supports. J. Phys. Chem. Lett. 2017, 8, 3564-3575. [CrossRef]

9. Spiro, M.; Griffin, P.W. Proof of an electron-transfer mechanism by which metals can catalyse oxidation-reduction reactions. J. Chem. Soc. D Chem. Commun. 1969, 1-2. [CrossRef]

10. Henglein, A. Reactions of organic free radicals at colloidal silver in aqueous solution. Electron pool effect and water decomposition. J. Phys. Chem. 1979, 83, 2209-2216. [CrossRef]

11. Meisel, D. Catalysis of Hydrogen Production in Irradiated Aqueous Solutions by Gold Sols. J. Am. Chem. Soc. 1979, 101, 6133-6135. [CrossRef]

12. Zidki, T.; Bar-Ziv, R.; Green, U.; Cohen, H.; Meisel, D.; Meyerstein, D. The effect of the nano-silica support on the catalytic reduction of water by gold, silver and platinum nanoparticles-nanocomposite reactivity. Phys. Chem. Chem. Phys. 2014, 16, 15422-15429. [CrossRef]

13. Ionita, P.; Conte, M.; Gilbert, B.C.; Chechik, V. Gold nanoparticle-initiated free radical oxidations and halogen abstractions. Org. Biomol. Chem. 2007, 5, 3504-3509. [CrossRef] [PubMed]

14. Ionita, P.; Gilbert, B.C.; Chechik, V. Radical mechanism of a place-exchange reaction of Au nanoparticles. Angew. Chem. Int. Ed. 2005, 44, 3720-3722. [CrossRef] [PubMed]

15. Zidki, T.; Cohen, H.; Meyerstein, D. Reactions of alkyl-radicals with gold and silver nanoparticles in aqueous solutions. Phys. Chem. Chem. Phys. 2006, 8, 3552-3556. [CrossRef]

16. Zhang, Z.; Berg, A.; Levanon, H.; Fessenden, R.W.; Meisel, D. On the interactions of free radicals with gold nanoparticles. J. Am. Chem. Soc. 2003, 125, 7959-7963. [CrossRef] [PubMed]

17. Lien, J.; Su, M.; Guo, T. Identification of Individual Reaction Steps in Complex Radical Reactions Involving Gold Nanoparticles. ChemPhysChem 2018, 19, 3328-3333. [CrossRef] [PubMed]

18. Zhang, J.; Mou, L.; Jiang, X. Surface chemistry of gold nanoparticles for health-related applications. Chem. Sci. 2020, 11. [CrossRef]

19. Dykman, L.; Khlebtsov, N. Gold nanoparticles in biomedical applications: Recent advances and perspectives. Chem. Soc. Rev. 2012, 41, 2256-2282. [CrossRef] [PubMed]

20. Yang, X.; Yang, M.; Pang, B.; Vara, M.; Xia, Y. Gold Nanomaterials at Work in Biomedicine. Chem. Rev. 2015, 115, 10410-10488. [CrossRef] [PubMed]

21. Fratoddi, I.; Venditti, I.; Cametti, C.; Russo, M.V. How toxic are gold nanoparticles? The state-of-the-art. Nano Res. 2015, 8, 1771-1799. [CrossRef]

22. Wang, H.; Mu, X.; He, H.; Zhang, X.D. Cancer Radiosensitizers. Trends Pharmacol. Sci. 2018, 39, 24-48. [CrossRef]

23. Herold, D.M.; Das, I.J.; Stobbe, C.C.; Iyer, R.V.; Chapman, J.D. Gold microspheres: A selective technique for producing biologically effective dose enhancement. Int. J. Radiat. Biol. 2000, 76, 1357-1364. [PubMed]

24. Butterworth, K.T.; McMahon, S.J.; Currell, F.J.; Prise, K.M. Physical basis and biological mechanisms of gold nanoparticle radiosensitization. Nanoscale 2012, 4, 4830-4838. [CrossRef] [PubMed]

25. Her, S.; Jaffray, D.A.; Allen, C. Gold nanoparticles for applications in cancer radiotherapy: Mechanisms and recent advancements. Adv. Drug Deliv. Rev. 2017, 109, 84-101. [CrossRef] [PubMed]

26. Rosa, S.; Connolly, C.; Schettino, G.; Butterworth, K.T.; Prise, K.M. Biological mechanisms of gold nanoparticle radiosensitization. Cancer Nanotechnol. 2017, 8. [CrossRef] [PubMed]

27. Howard, D.; Sebastian, S.; Le, Q.V.C.; Thierry, B.; Kempson, I. Chemical mechanisms of nanoparticle radiosensitization and radioprotection: A review of structure-function relationships influencing reactive oxygen species. Int. J. Mol. Sci. 2020, 21, 579. [CrossRef]

28. Guo, T. Physical, chemical and biological enhancement in X-ray nanochemistry. Phys. Chem. Chem. Phys. 2019, 21, 15917-15931. [CrossRef]

29. Shcherbakov, V.; Denisov, S.A.; Mostafavi, M. On the Primary Water Radicals' Production in the Presence of Gold Nanoparticles: Electron Pulse Radiolysis Study. Nanomaterials 2020, 10, 2478. [CrossRef]

30. Newton, G.L.; Milligan, J.R. Fluorescence detection of hydroxyl radicals. Radiat. Phys. Chem. 2006, 75, 473-478. [CrossRef]

31. Gomes, A.; Fernandes, E.; Lima, J.L.F.C. Fluorescence probes used for detection of reactive oxygen species. J. Biochem. Biophys. Methods 2005, 65, 45-80. [CrossRef] [PubMed]

32. Link, S.; El-Sayed, M.A. Size and temperature dependence of the plasmon absorption of colloidal gold nanoparticles. J. Phys. Chem. B 1999, 103, 4212-4217. [CrossRef] 
33. Feigenbrugel, V.; Loew, C.; Le Calvé, S.; Mirabel, P. Near-UV molar absorptivities of acetone, alachlor, metolachlor, diazinon and dichlorvos in aqueous solution. J. Photochem. Photobiol. A Chem. 2005, 174, 76-81. [CrossRef]

34. Buxton, G.V.; Greenstock, C.L.; Helman, W.P.; Ross, A.B. Critical Review of Rate Constants for Reactions of Hydrated Electrons, Hydrogen Atoms and Hydroxyl Radicals (OH/O-) in Aqueous Solution. J. Phys. Chem. Ref. Data 1988, 17. [CrossRef]

35. Asmus, K.D.; Mockel, H.; Henglein, A. Pulse Radiolytic Study of the Site of OH Radical Attack on Aliphatic Alcohols in Aqueous Solution. J. Phys. Chem. 1973, 77, 1218-1221. [CrossRef]

36. Henglein, A.; Lilie, J. Storage of Electrons in Aqueous Solution: The Rates of Chemical Charging and Discharging the Colloidal Silver Microelectrode. J. Am. Chem. Soc. 1981, 103, 1059-1066. [CrossRef]

37. Belloni, J. Nucleation, growth and properties of nanoclusters studied by radiation chemistry: Application to catalysis. Catal. Today 2006, 113, 141-156. [CrossRef]

38. Pan, X.M.; Schuchmann, M.N.; Von Sonntag, C. Oxidation of benzene by the $\mathrm{OH}$ radical. A product and pulse radiolysis study in oxygenated aqueous solution. J. Chem. Soc. Perkin Trans. 2 1993, 289-297. [CrossRef]

39. Wang, D.; Schuchmann, H.P.; Sonntag von, C. Phenylalanine: Its ·OH and SO4.--Induced Oxidation and Decarboxylation. A Pulse Radiolysis and Product Analysis Study. Naturforsch. B Chem. Sci. 1993, 48, 761-770. [CrossRef]

40. Minai, L.; Yeheskely-Hayon, D.; Yelin, D. High levels of reactive oxygen species in gold nanoparticle-targeted cancer cells following femtosecond pulse irradiation. Sci. Rep. 2013, 3, 2146. [CrossRef] [PubMed]

41. Jawaid, P.; Rehman, M.U.; Zhao, Q.L.; Misawa, M.; Ishikawa, K.; Hori, M.; Shimizu, T.; Saitoh, J.-i.; Noguchi, K.; Kondo, T. Small size gold nanoparticles enhance apoptosis-induced by cold atmospheric plasma via depletion of intracellular GSH and modification of oxidative stress. Cell Death Discov. 2020, 6, 83. [CrossRef] [PubMed]

42. Pan, Y.; Leifert, A.; Ruau, D.; Neuss, S.; Bornemann, J.; Schmid, G.; Brandau, W.; Simon, U.; Jahnen-Dechent, W. Gold nanoparticles of diameter $1.4 \mathrm{~nm}$ trigger necrosis by oxidative stress and mitochondrial damage. Small 2009, 5, 2067-2076. [CrossRef] [PubMed]

43. Seong, M.; Lee, D.G. Reactive oxygen species-independent apoptotic pathway by gold nanoparticles in Candida albicans. Microbiol. Res. 2018, 207, 33-40. [CrossRef] [PubMed]

44. Louit, G.; Foley, S.; Cabillic, J.; Coffigny, H.; Taran, F.; Valleix, A.; Renault, J.P.; Pin, S. The reaction of coumarin with the OH radical revisited: Hydroxylation product analysis determined by fluorescence and chromatography. Radiat. Phys. Chem. 2005, 72, 119-124. [CrossRef]

45. Cheng, N.N.; Starkewolf, Z.; Davidson, R.A.; Sharmah, A.; Lee, C.; Lien, J.; Guo, T. Chemical Enhancement by Nanomaterials under X-ray Irradiation. J. Am. Chem. Soc. 2012, 1950-1953. [CrossRef] [PubMed]

46. Liu, Y.; Liu, X.; Jin, X.; He, P.; Zheng, X.; Dai, Z.; Ye, F.; Zhao, T.; Chen, W.; Li, Q. The dependence of radiation enhancement effect on the concentration of gold nanoparticles exposed to low- and high-LET radiations. Phys. Med. 2015, 31, 210-218. [CrossRef] [PubMed]

47. Gilles, M.; Brun, E.; Sicard-Roselli, C. Quantification of hydroxyl radicals and solvated electrons produced by irradiated gold nanoparticles suggests a crucial role of interfacial water. J. Colloid Interface Sci. 2018, 525, 31-38. [CrossRef] [PubMed] 